\title{
Incorporating Expert Judgement into Life Insurance and Life Takaful Companies' Efficiency Measurement Through DEA- AR/FAHP Approach
}

Nur Azlina Abd Aziz, Nor Faradilah Mahad, Jamilah Mohd Mahyideen and Eley Suzana Kasim

To Link this Article: http://dx.doi.org/10.6007/IJARBSS/v11-i11/11250

DOI:10.6007/IJARBSS/v11-i11/11250

Received: 05 September 2021, Revised: 27 September 2021, Accepted: 16 October 2021

Published Online: 04 November 2021

In-Text Citation: (Aziz et al., 2021)

To Cite this Article: Aziz, N. A. A., Mahad, N. F., Mahyideen, J. M., \& Kasim, E. S. (2021). Incorporating Expert Judgement into Life Insurance and Life Takaful Companies' Efficiency Measurement Through DEAAR/FAHP Approach. International Journal of Academic Research in Business and Social Sciences, 11(11), 202-221.

\section{Copyright: (c) 2021 The Author(s)}

Published by Human Resource Management Academic Research Society (www.hrmars.com) This article is published under the Creative Commons Attribution (CC BY 4.0) license. Anyone may reproduce, distribute, translate and create derivative works of this article (for both commercial and non-commercial purposes), subject to full attribution to the original publication and authors. The full terms of this license may be seen at: http://creativecommons.org/licences/by/4.0/legalcode

$$
\text { Vol. 11, No. 11, 2021, Pg. } 202-221
$$




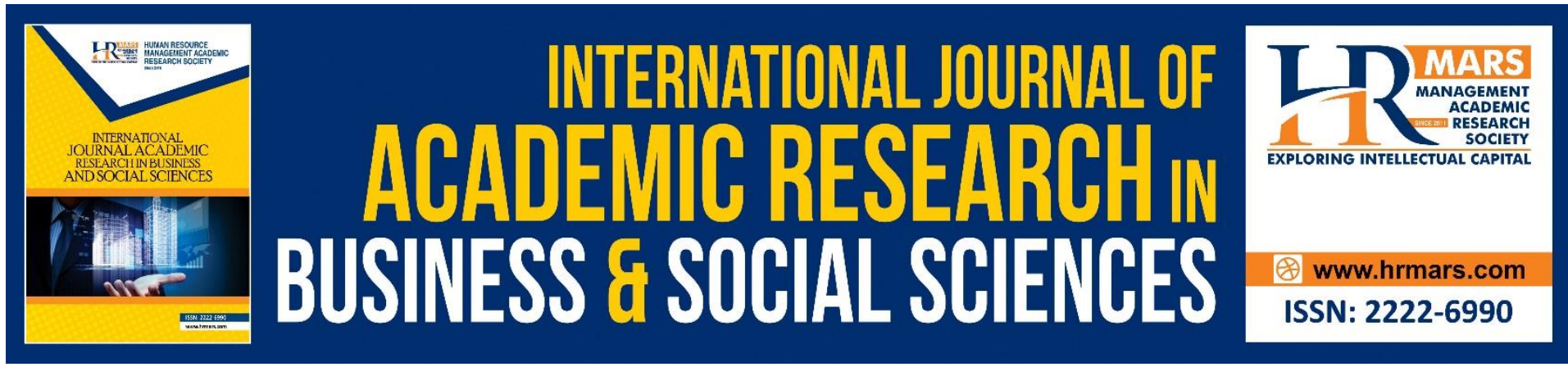

\title{
Incorporating Expert Judgement into Life Insurance and Life Takaful Companies' Efficiency Measurement Through DEA-AR/FAHP Approach
}

\author{
Nur Azlina Abd Aziz ${ }^{1}$, Nor Faradilah Mahad ${ }^{1}$, Jamilah Mohd \\ Mahyideen ${ }^{2}$ and Eley Suzana Kasim ${ }^{3,4}$ \\ ${ }^{1}$ Faculty of Computer and Mathematical Sciences (FSKM), Universiti Teknologi MARA \\ Cawangan Negeri Sembilan, Kampus Seremban, Malaysia, ${ }^{2}$ Faculty of Business and \\ Management, Universiti Teknologi MARA Cawangan Negeri Sembilan, Kampus Seremban, \\ Malaysia, ${ }^{3}$ Faculty of Accountancy, Universiti Teknologi MARA Cawangan Negeri Sembilan, \\ Kampus Seremban, Malaysia, ${ }^{4}$ Accounting Research Institute, Universiti Teknologi MARA, \\ Shah Alam, Selangor, Malaysia \\ Email: faradilah315@uitm.edu.my
}

\begin{abstract}
Increased competition within the insurance industry has led to the critical need for insurance companies to utilise their resources efficiently. Data Envelopment Analysis (DEA) model has been widely used to measure the relative efficiency of these companies. However, a limitation of the conventional model indicates that certain crucial factors were ignored in the analysis resulting in unrealistic efficiency outcomes. Hence, the present study aimed to provide a more robust efficiency measurement by incorporating the subjective value of judgement in the standard DEA through a hybrid model which integrates Constant Return Scale model of DEA, Assurance Region Type I (ARI), and Fuzzy Analytic Hierarchy Process (FAHP) method. This proposed DEA-AR/FAHP model was applied on the data gathered from 22 Malaysian life insurance and takaful companies between 2017 and 2018. Findings revealed that the model provides an improved efficiency assessment through the elimination of zero weights and hence deliver more realistic results.
\end{abstract}

Keywords: Efficiency, Insurance, Data Envelopment Analysis, Assurance Region Type I, Fuzzy Analytic Hierarchy Process.

\section{Introduction}

Over the years, the life insurance sector has become an essential component of the financial sector. In Malaysia, the insurance industry has witnessed rapid development every year where the insurance sector has emerged as an important factor in contributing to the economic development of the country (Masud et al., 2019). The Life Insurance Association of Malaysia (LIAM) stated that the coverage of life insurance had increased by $9.6 \%$ with a total hit of RM1.51 trillion in comparison to the RM 1.38 trillion in 2017 (Life Insurance Association of Malaysia, 2019). As reported by the central bank, Bank Negara Malaysia, presently there 
are 14 registered life insurance companies and 15 registered takaful operators in Malaysia (Bank Negara Malaysia, 2020).

Takaful is often an alternative to the conventional insurance policies in some Muslim countries. Basically, Takaful protection is a joint guarantee in which participants contribute their own shares of premiums into a pool and mutually agree to compensate those participants who suffer from an insured peril (Matsawali et al., 2012). There are, however, several differences between conventional insurance and the Islam-based Takaful protection. First, the philosophy behind each product is different. Takaful is based on the idea of social solidarity, cooperation, and joint indemnification of the losses of members. On the contrary the conventional insurance is a device, which reduces the risk of insured party via the transfer of particular risks to another party i.e., the insurer. The insurer then offers a restoration, at least in part, of the economic losses suffered by the insured. Second, there is no exchange of risk between the insurer and the insured in takaful, unlike the insurance. The risk under takaful is distributed among participants who agree to jointly assume the risk. Finally, takaful does not involve in uncertainty (Al-Gharar), gambling (Al-Maisir), and interest (Riba), which conventional insurance does (Matsawali et al., 2012).

The intense competition in the Malaysian insurance industry had driven life insurance and takaful companies to operate efficiently (Wang et al., 2019). Insurance companies should make necessary changes to keep up with the current trend. However, the top management of life insurance and takaful companies were concerned whether their companies had utilised their resources efficiently to produce outputs. Nonetheless, transformations and changes could only be made after the insurance firms had gone through the efficiency evaluation and the results were compared to their competitors. It is however, challenging to measure the efficiency of life insurance companies because these companies are multi-product companies that use multiple inputs and produce multiple outputs. The Data Envelopment Analysis (DEA) is an effective tool to measure the efficiency of a group of peer decision-making units (DMUs). The education, banking, agriculture, healthcare, finance, and many other sectors had applied DEA (Cooper et al., 2006) because it has the ability to handle multiple inputs and outputs. Additionally, the DEA is weight flexible and therefore, is free to input and output factors' weight values to obtain the highest efficiency score (Coelli et al., 2005; Khalili et al., 2010). However, the total flexibility to choose weights can create some problems because a DMU may be identified as efficient by assigning zero weight to certain input and output factors (Bal et al., 2010; Premachandra, 2001). When a zero weight is assigned to any input and output, the respective factors would be eliminated in the efficiency assessment despite of its significance and suggestions to be included. In some cases, selected weights might conflict with the preference of decision makers on the importance of inputs and outputs. This could result in unrealistic efficiency outcomes (Cooper et al., 2006).

The present study intended to reduce the occurrences of impractical and unrealistic variable of weights such as the zero weights by incorporating experts' opinions in DEA to evaluate the efficiency of 22 Malaysian life insurance and takaful companies from 2017 to 2018. Therefore, this study proposed a DEA model with Assurance Region type I (ARI) and Fuzzy Analytic Hierarchy Process (FAHP). FAHP was applied to elicit the experts' opinion on the importance of inputs and outputs whereas the Assurance Region Method (AR) was used to allow incorporation of value judgement in DEA. The model was referred to as the DEAAR/FAHP model. 


\section{Literature Review}

Data Envelopment Analysis

Data Envelopment Analysis (DEA) is a prominent tool used by many researchers to measure the efficiency or performance of firms in a wide range of industries. Charnes et al. (1978) pioneered the Data Envelopment Analysis (DEA) model. The DEA model is computed as follows: Let $n$ be the number of DMUs to be evaluated whereby each $D M U_{j}(j=1,2, \ldots, n)$ consumes $m$ inputs to produce $s$ outputs, where $s$ can be products or services. Next, $x_{i j}(i=1,2, \ldots, m)$ and $y_{r j}(r=1,2, \ldots, s)$ represent the amount of input $i$ and output $r$ produced by the $j^{\text {th }} \mathrm{DMU}$, respectively. Besides that, $u_{r}$ and $v_{i}$ represent the unknown weights for outputs and inputs, respectively, whereas $D M U_{0}$ is the unit to be evaluated. The efficiency of $D M U_{0}$ can be evaluated by solving the following linear programming problem:

$$
\begin{array}{ll}
\text { Maximize } & \theta_{o}=\sum_{r=1}^{s} u_{r} y_{r o} \\
\text { subject to } & \sum_{r=1}^{m} v_{i} x_{i o}=1, \\
& \sum_{r=1}^{s} u_{r} y_{r j}-\sum_{i=1}^{m} v_{i} x_{i j} \leq 0 ; j=1,2, \ldots, n \\
& u_{r}, v_{i} \geq 0 .
\end{array}
$$

Model (1) adopts the constant return to scale (CRS) technology, which is referred to as CCR input-oriented model. The formulation obtains the relative efficiency of $D M U_{0}$ by assigning weights to outputs $s\left(u_{r}\right)$ and inputs $m\left(v_{i}\right)$ to ensure the weighted sum of outputs to that of inputs $\left(\theta_{0}\right)$ is maximised. Furthermore, the first constraint ensures that the ratio efficiency values are confined to 1 . Therefore, a finite number of optimal solutions are guaranteed. Based on the formulation above, values of $\theta$ satisfies $0 \leq \theta \leq 1$. Meanwhile, $D M U_{0}$ is identified as CCR efficient if $\theta=1$ and there is at least one optimal $\left(v^{*}, u^{*}\right)$ with $v^{*} \geq 0$ and $u^{*} \geq 0$; otherwise, it is inefficient.

\section{Assurance Region Type I (AR1)}

Assurance Region is a popular weight restriction technique, which has been successfully applied to a wide range of applications because a practical and straightforward method to incorporate rational judgement based on the DEA models (Dyson et al., 2001). There are two types of AR: (a) Assurance type I (ARI) and (b) Assurance Region type II (ARII). ARI is confined between the ratios of input weights or output weights. On the other hand, ARII creates bounds between ratios that link input to output weights (Khalili et al., 2010). This study chose to apply ARI over other weight restriction methods because DEA model in presence of weight restriction $A R I$ is always feasible in which at least one DMU will be found efficient (Allen et al., 1997). Lower and upper bounds of weight ratios between input or output weights were developed as follows:

For each pair of input $\left(x_{p}, x_{q}\right)$, the weight $\frac{v_{p}}{v_{q}}$ should be bounded by $A_{p, q}$ and $B_{p, q}$, which represented the lower and upper bounds, respectively, for allowable values of ratio 
weight $\frac{v_{p}}{v_{q}}$. Notation $v_{p}$ represented the weight of input $x_{p}$ whereas $v_{q}$ denoted the weight of input $x_{q}$. Therefore, the relative importance of any two input factors is as follows:

$$
A_{p, q} \leq \frac{v_{p}}{v_{q}} \leq B_{p, q} \text { where } p \neq q
$$

Similarly, for each pair of output $\left(y_{p}, y_{q}\right)$, the lower and upper bounds of ratio for any two outputs were $a_{p, q}$, and $b_{p, q}$, respectively.

$$
a_{p, q} \leq \frac{u_{p}}{u_{q}} \leq b_{p, q} \text { where } p \neq q
$$

where, $u_{p}$ represents weight of output $y_{p}$ and $u_{q}$ denotes the weight of output $y_{q}$.

\section{Fuzzy Analytical Hierarchy Process (FAHP)}

Multi Criteria Decision Making (MCDM) problem evaluates and chooses a finite set of alternatives based on a set of criteria that are often in conflict. The problem is described in a hierarchy, which represents the simplest type of functional dependence of one level or the component of a system on another in a sequential manner (Saaty, 1994). Analytic Hierarchy Process (AHP) is the most common and popular MCDM method. This method is beneficial because it can easily handle multiple criteria, easier to understand, and can effectively handle both the qualitative and quantitative data (Kumar \& Ganesh, 1996). AHP is a theory of relative measurement on absolute scales of both tangible and intangible criteria based on the paired comparison judgment of knowledgeable experts (Ozdemir \& Saaty, 2006). AHP involves the principles of decomposition, pair-based comparisons, and priority vector generation and synthesis (Kahraman et al., 2004).

However, this method is often criticised because of its imbalanced scale of judgements and the inability to adequately handle the inherent uncertainty and imprecision of the pairwise comparison process (Deng, 1999). Although AHP captures the experts' knowledge, the conventional AHP still cannot reflect the human thinking style and therefore, Fuzzy Analytic Hierarchy Process (FAHP) method, a fuzzy extension of AHP, was developed to solve the hierarchical fuzzy problems (Kahraman et al., 2004). Attempts to handle this uncertainty, imprecision, and subjective human judgments were carried out based on the probability theory and/or fuzzy set theory (Deng, 1999). Zadeh (1965) introduced fuzzy sets theory, to rationalise uncertainty associated with impression or vagueness, and analogous to human thoughts. An expert's uncertain judgment can be represented by a fuzzy number. A triangular fuzzy number (TFN) is a special kind of fuzzy number, in which the function of the membership is defined by three real numbers. Hence, $(I, m, u)$ where $I, m$ and $u$ are the lower, mean, and upper bounds of the TFN. Figure 1 illustrates this membership function. The membership function $\mu$ represented the degree to which any given element $x$ in the domain $X$ belonged to the fuzzy number $A$ (Vahidnia et al., 2009). 


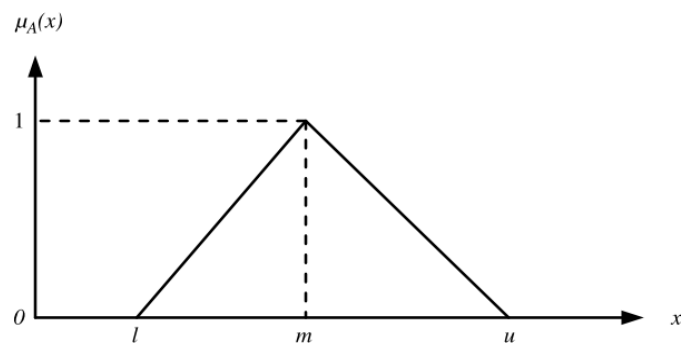

Figure 1. Triangular Fuzzy Number $A$

FAHP method retains many of the advantages enjoyed by conventional AHP. FAHP remained popular as a result of its flexibility and the ability to combine with other techniques (e.g., The Technique for Order of Preference by Similarity to Ideal Solution (TOPSIS), Linear Programming (LP) and its simplicity of implementation (Kubler et al., 2016). Many past studies had applied the FAHP methods and applications. Van Laarhoven and Pedrycz (1983) were the first to apply fuzzy logic principle to AHP. Buckley (1985) initiated trapezoidal fuzzy numbers to express the decision maker's evaluation on alternatives with respect to each criterion whereas Van Laarhoven and Pedrycz (1983) used the TFNs.

On the other hand, Chang (1996) introduced a new approach to handle FAHP with the use of TFNs for the pair-based comparison scale of FAHP. Additionally, Chang (1996) also introduced the extent analysis method for the synthetic extent values of the pair-based comparisons. The extent analysis method in FAHP approach had been employed in numerous applications as a result of its computational simplicity. However, this method was unable to derive the accurate weights from a fuzzy or crisp comparison matrix because the weights did not represent the relative importance of decision criteria or alternatives (Wang et al., 2008), which resulted in problems such as poor robustness, unreasonable priorities, and information loss (Kubler et al., 2016). Furthermore, this method could assign zero weight to a decision criterion or alternative, which might not be considered in the decision analysis (Wang et al., 2008; Vahidnia et al., 2009). Thus, the decision criterion or alternative should be removed from the fuzzy comparison matrix not be included from the beginning (Wang et al., 2008). However, this paper employed the geometric mean method in FAHP. Buckley (1985) utilised the geometric mean method to calculate fuzzy weights. The method was used to evaluate the fuzzy weights for each fuzzy matrix and were combined in a typical way to derive the final fuzzy weights for the alternatives and rank them based on the final fuzzy weights.

\section{Efficiency in Life Insurance Sector}

Multiple studies had been carried out to analyse the efficiency level for the insurance sectors. These studies had therefore, adopted different approaches to analyse the efficiency level. One of them is the non-parametric approach. DEA is one of the most frequently used method for the non-parametric approach. Eling and Luhnen (2010) in their study reported that 55 out of 95 surveys used DEA as a method to measure the efficiency of the insurance industry. A number of studies measure the efficiency of the insurance industry at a national level. This specific evidence could be obtained from Malaysia (Mansur \& Radam, 2000; Saad et al., 2006; Saad \& Idris, 2011; Saad, 2012; Antonio et al., 2013; Chen at al., 2014), Indonesia (Abidin \& Cabanda, 2011; Rusydiana \& Nugroho, 2017; Abd Majid et al., 2017), Saudi Arabia (Almulhim, 2019), Taiwan (Kao \& Hwang, 2008), and the United States (US) (Cummins, et al., 1999; Meador, et al., 2000). 
Abidin and Cabanda (2011) employed DEA on 23 non-life insurance companies between 2005 and 2007 to examine the performance of Indonesia's insurance industry. The study found a positive relationship between the size of the firm and its efficiency level. The larger the insurance company, the more efficient it operated. Based on a similar method, Rusydiana and Nugroho (2017) measured the efficiency level of 8 life insurance companies from 2011 to 2015 via three inputs and 2 outputs. The obtained results showed that the conventional insurance institution was relatively more efficient than the Sharia insurance because the latter had a smaller market share. Additionally, the results also revealed that out of the 39 DMUs, 15 were perfect and efficient DMUs (100\%) whereas 24 were inefficient. Out of the 24 DMUs, 7 DMUs were increasing returns to scale (IRS) and 17 DMUs were decreasing returns to scale (DRS).

Mansur and Radam (2000) conducted one of the earliest studies on the efficiency of the insurance industry in Malaysia. They evaluated the productivity and efficiency performance of 12 life insurance companies between 1987 and 1997 via the non-parametric Malmquist Index. The result indicated that the firm's ability to compete efficiently would determine growth of the insurance industry in future. It also concluded that both the technical efficiency and technical progress contributed to the overall productivity of the industry. On the other hand, Saad et al (2006) adopted the Malmquist index and extended Mansor and Radam's (2000) study by including the Islamic insurance companies or takaful operators. The study was conducted from 2002 to 2005 based on 12 life insurance companies and one takaful operator. Overall, the study indicated that the industry's efficiency declined between 2002 and 2004 but observed a slight increase in 2005.

Saad (2012) overcame the limitations in Saad et al (2006) and included more takaful operators. Saad (2012) examined the examined the efficiency between general takaful and the conventional insurance industry in Malaysia from 2007 to 2009. The output-input data consisted of 28 panels of general takaful and conventional insurance companies. Based on the DEA approach, the study found that the takaful companies were less efficient in comparison to their conventional counterparts. In a similar study, Antonio et al (2013) compared the efficiency of takaful and conventional insurance companies between 2009 and 2011. Based on data for 7 takaful operators and 19 conventional insurance companies, the study showed that conventional insurance companies are more efficient than takaful operators in 2011 and thus consistent with (Saad, 2012).

Although the efficiency of the insurance industry was mostly measured at the national level, there had been instances of inter-country comparisons between insurance firms (Saad \& Idris, 2011; Eling \& Luhnen, 2009). Saad and Idris (2011) examined the efficiency of the life insurance industry between Brunei and Malaysia and employed the generalised outputoriented Malmquist index from 2000 to 2005 based on the output-input data, which consisted of 9 panel life insurance firms in Malaysia and 2 in Brunei. This study utilised two inputs and two outputs, namely, commission and management as well as premium and net investment income, respectively. Findings revealed that on average, the TFP of the life insurance industry resulted from factors such as efficiency and technical changes. Additionally, the main source of shift in efficiency was a result of the scale efficiency rather than pure efficiency.

There were no recent studies integrating DEA and Fuzzy Analytic Hierarchy Process (FAHP) to evaluate efficiency of insurance companies despite numerous research works on DEA to measure the efficiency of insurance industry. Therefore, the present study had contributed its respect to previous works of literature by integrating DEA with the Fuzzy Analytic Hierarchy Process (FAHP) and applying the hybrid method to measure the efficiency 
of life insurance and takaful companies in Malaysia. This study also incorporated the value judgement on the importance of inputs and outputs to measure the efficiency of these insurance companies.

\section{Model Development}

Inputs, Outputs, and Data Sources

In this study, two inputs and two outputs were chosen to evaluate the efficiency of 22 life insurance and takaful companies in Malaysia from the period of 2017 to 2018. The inputs consisted of fees and commission; and management expenses that represented the amount paid by the company. These inputs were selected because both the expenses provided a significant impact on the performance on the company. Besides, the outputs chosen for the present study were net premium and generated investment income, which were the two significant revenues for an insurance and a takaful company (Shieh et al., 2020).

This case study was made up of 13 life insurance companies and 9 Takaful companies in Malaysia. These companies were Allianz Life Insurance Malaysia Berhad, AIA Berhad, AXA Affin Life Insurance Berhad, Great Eastern Life Assurance (Malaysia Berhad), Manulife Insurance Berhad, MCIS Insurance Berhad. Prudential Assurance Malaysia Berhad, Sun Life Malaysia Assurance Berhad, Tokio Marine Life Insurance Malaysia Berhad, Gibraltar BSN Life Berhad, Zurich Life Insurance Malaysia Berhad, Hong Leong Assurance Berhad, AmMetLife Assurance Berhad, HSBC Amanah Takaful Berhad, Prudential BSN Takaful Berhad, Sun Life Malaysia Takaful Berhad, Zurich Takaful Malaysia Berhad, AIA Public Takaful Berhad, Etiqa Family Takaful Berhad, AmMetLife Takaful Berhad, Great Eastern Takaful, and Hong Leong MSIG Takaful Berhad. Each life insurance and takaful company was regarded as a DMU. The data was retrieved from the annual reports of the companies. The data was normalised to ensure it was dimensionless. Figure 2 illustrates the model of this study.

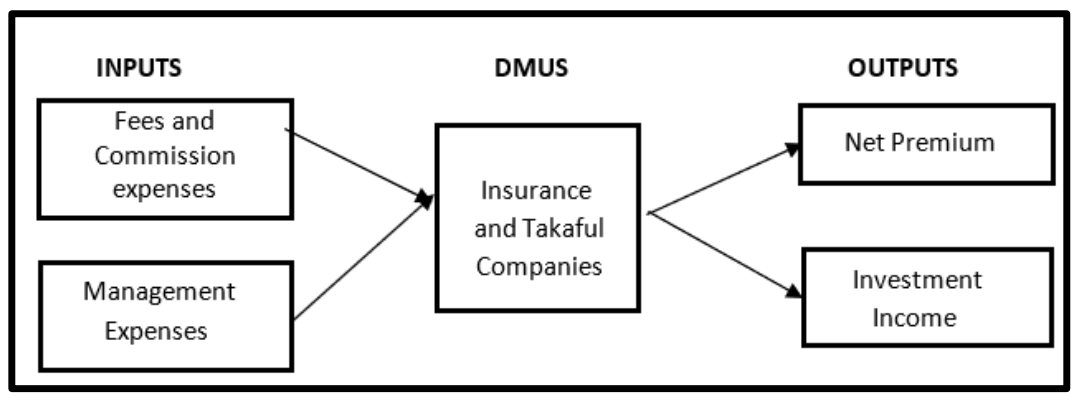

Figure 2. Model of the study

\section{Determination of bounds in ARI}

This study established an expert group of four senior managers from various companies' members. The four experts were two-unit managers (DM1), one direct manager (DM2), agency manager (DM3), and agency manager (DM4) with at least 10 years of management experience in life insurance and takaful companies. Based on their experiences, their subjective judgement on importance of inputs and outputs will be elicited where the experts may give different weights. Therefore, an AHP pair-based comparison was applied to elicit the experts' subjective judgements. The Fuzzy AHP method was utilised to determine weight of the input and output factors from each expert. These weights were used to set lower and upper bounds of ratio of input and output. Finally, these additional constraints were added to the standard CCR input oriented model. 


\section{Geometric Mean Method in FAHP Framework}

The geometric mean method in FAHP had seven steps that were implemented in the present study to determine the relative important weights for the criteria and alternatives (Buckley, 1985) as follows:

Step 1. Construct a hierarchy structure for the MCDM problems.

Step 2. Data scaling and the establishment of pair-based comparison for each criterion (attribute) with respect to criteria and pair-based comparison for each alternative with respect to each criterion. Table 1 shows the triangular fuzzy importance scale used in this study (Vahidnia et al., 2009).

Table 1. Triangular Fuzzy Importance Scale

\begin{tabular}{lll}
\hline Linguistic Scale & TFNs Scale & TFNs Reciprocal Scale \\
\hline Equally strong & $(1,1,1)$ & $(1,1,1)$ \\
$\begin{array}{l}\text { Moderately } \\
\text { strong }\end{array}$ & $(2,3,4)$ & $\left(\frac{1}{4}, \frac{1}{3}, \frac{1}{2}\right)$ \\
Strong & $(4,5,6)$ & $\left(\frac{1}{6}, \frac{1}{5}, \frac{1}{4}\right)$ \\
Very Strong & $(6,7,8)$ & $\left(\frac{1}{8}, \frac{1}{7}, \frac{1}{6}\right)$ \\
Extremely & $(9,9,9)$ & $\left(\frac{1}{9}, \frac{1}{9}, \frac{1}{9}\right)$ \\
strong & & $\left(\frac{1}{3}, \frac{1}{2}, 1\right),\left(\frac{1}{5}, \frac{1}{4}, \frac{1}{3}\right),\left(\frac{1}{7}, \frac{1}{6}, \frac{1}{5}\right),\left(\frac{1}{9}, \frac{1}{8}, \frac{1}{7}\right)$ \\
\hline Intermediate & $(1,2,3),(3,4,5),(5,6,7),(7,8,9)$ &
\end{tabular}

Step 3. Compute the pair-based contribution matrix. The pair-based contribution matrix was shown as:

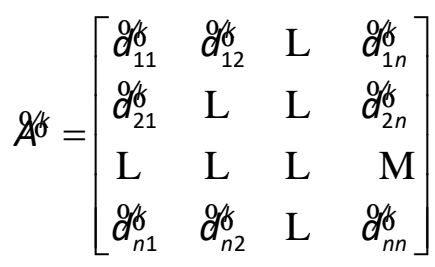

where $d_{i j}^{k}$ indicated the $k^{\text {th }}$ decision maker's preference of $i^{\text {th }}$ criterion over a $j^{\text {th }}$ criterion, via fuzzy triangular numbers. For example, $d_{12}^{6}$ represented the first decision maker's preference of the first criterion over the second criterion. If there was more than one decision maker, preferences of each decision maker $d_{i j}^{6}$ were averaged and $\left(\mathscr{d}_{i j}\right)$ is calculated as

$$
\tilde{d}_{i j}=\left(l_{i j}, m_{i j}, u_{i j}\right)=\left(\min \left(l_{i j}^{k}\right) \text {, average }\left(m_{i j}^{k}\right), \max \left(u_{i j}^{k}\right)\right)
$$

Thus, the pair-based contribution matrix was updated as

$$
\tilde{A}=\left[\begin{array}{cccc}
\tilde{d}_{11} & \cdots & \cdots & \tilde{d}_{1 n} \\
\tilde{d}_{21} & \ddots & \cdots & \tilde{d}_{2 n} \\
\vdots & \vdots & \ddots & \vdots \\
\tilde{d}_{n 1} & \cdots & \cdots & \tilde{d}_{n n}
\end{array}\right]
$$

Step 4. Calculate the geometric mean of fuzzy comparison value of each criterion via 


$$
\tilde{r}_{i}=\left(\prod_{j=1}^{n} \tilde{d}_{i j}\right)^{\frac{1}{n}}, i=1,2, \ldots, n .
$$

where $\tilde{r}_{i}$ still represented triangular values.

Step 5. Compute the fuzzy weight for each criterion $\left(\tilde{w}_{i}\right)$, by finding the vector summation for each $\tilde{r}_{i}$ and computing the reverse power of the summation vector and arranging it in an ascending order. To compute $\tilde{w}_{i}$, a reverse vector was multiplied with each $\tilde{r}_{i}$ as

$$
\tilde{w}_{i}=\tilde{r}_{i} \otimes\left(\tilde{r}_{1} \oplus \tilde{r}_{2} \oplus \ldots \oplus \tilde{r}_{n}\right)^{-1}=\left(l w_{i}, m w_{i}, u w_{i}\right)
$$

Step 6. Since $\tilde{w}_{i}$ were still triangular fuzzy numbers, they needed to be defuzzied via

$$
M_{i}=\frac{l w_{i}+m w_{i}+u w_{i}}{3}
$$

where $M_{i}$ was a non-fuzzy number.

Step 7. Compute the normalised relative weights for each criterion, $N_{i}$ using

$$
N_{i}=\frac{M_{i}}{\sum_{i=1}^{n} M_{i}}
$$

These seven steps were applied to find the normalised relative weights of both criteria (attributes) and the alternatives. The alternative with the highest value was proposed as the best alternative for the decision maker. Therefore, the sum of the normalised relative weights should be 1.

\section{Results and Discussions}

Bounds obtained in Assurance Region

The present study applied the Geometric Mean Method in FAHP to determine the importance of the input and output factors. The input factors comprised of fees and commission expenses, and management expenses whereas the output factors consisted of net premium and the investment income. The subjective opinions from the experts obtained by Mohamad et al. (2019) was adapted. The Geometric Mean Method n FAHP was then demonstrated based on the evaluation of relative weights for the input factors of DM1. Table 2 shows the pairwise comparison matrix for the input factors.

Table 2. Comparison Matrix for the Input Factors

\begin{tabular}{lll}
\hline$C_{n}$ & $\begin{array}{l}\text { Fees and Commission } \\
\text { Expenses }\left(C_{1}\right)\end{array}$ & $\begin{array}{l}\text { Management Expenses } \\
\left(C_{2}\right)\end{array}$ \\
\hline $\begin{array}{l}\text { Fees and Commission Expenses } \\
\left(C_{1}\right)\end{array}$ & $(1,1,1)$ & $\left(\frac{1}{9}, \frac{1}{9}, \frac{1}{9}\right)$ \\
Management Expenses $\left(C_{2}\right)$ & $(9,9,9)$ & $(1,1,1)$ \\
\hline
\end{tabular}

The geometric mean of fuzzy comparison value of input factors, $\tilde{r}_{i}$ is calculated using equation (7). 


$$
\begin{aligned}
& \tilde{r}_{1}=\left[\left(1 \times \frac{1}{9}\right)^{\frac{1}{2}},\left(1 \times \frac{1}{9}\right)^{\frac{1}{2}},\left(1 \times \frac{1}{9}\right)^{\frac{1}{2}}\right]=\left(\frac{1}{3}, \frac{1}{3}, \frac{1}{3}\right) \\
& \tilde{r}_{2}=\left[(9 \times 1)^{\frac{1}{2}},(9 \times 1)^{\frac{1}{2}},(9 \times 1)^{\frac{1}{2}}\right]=(3,3,3)
\end{aligned}
$$

Table 3 shows the geometric means of fuzzy comparison values of each input factor, the vector summation for each $\tilde{r}_{i}$, and the reverse power of the summation vector.

Table 3. Geometric Mean of Fuzzy Comparison Values

\begin{tabular}{|l|l|l|l|}
\hline Criteria $\left(C_{n}\right)$ & $\tilde{r}_{i}$ & $\frac{1}{3}$ \\
\hline $\begin{array}{l}\text { Fees and Commission } \\
\text { Expenses }\left(C_{1}\right)\end{array}$ & $\frac{1}{3}$ & $\frac{1}{3}$ & 3 \\
\hline $\begin{array}{l}\text { Management Expenses } \\
\left(C_{2}\right)\end{array}$ & 3 & 3 & $\frac{10}{3}$ \\
\hline TOTAL & $\frac{10}{3}$ & $\frac{10}{3}$ & 0.3 \\
\hline REVERSE & 0.3 & 0.3 & 0.3 \\
\hline ASCENDING ORDER & 0.3 & 0.3 & \\
\hline
\end{tabular}

Equation (8) was used to compute the fuzzy weight for each input factor $\left(\tilde{w}_{i}\right)$. For instance, the fuzzy weight of the fees and commission expenses $\left(\tilde{w}_{1}\right)$ was calculated as follows:

$$
\tilde{w}_{1}=\left(\left(\frac{1}{3} \times 0.3\right),\left(\frac{1}{3} \times 0.3\right),\left(\frac{1}{3} \times 0.3\right)\right)=(0.1,0.1,0.1)
$$

Table 4 shows the relative fuzzy weight of input factor, the averaged, and normalised relative weights for input factor.

Table 4. The Relative Fuzzy Weights, the Averaged and the Normalised Relative Weights of Each Input Factor

\begin{tabular}{llllll}
\hline Criteria $\left(C_{n}\right)$ & $\tilde{w}_{i}$ & & & $M_{i}$ & $N_{i}$ \\
\hline Fees and Commission Expenses $\left(C_{1}\right)$ & 0.1 & 0.1 & 0.1 & 0.1 & 0.1 \\
Management Expenses $\left(C_{2}\right)$ & 0.9 & 0.9 & 0.9 & 0.9 & 0.9 \\
\hline Sum & & & & 1 & 1 \\
\hline
\end{tabular}

Equation (9) was employed to defuzzy $\tilde{w}_{i} . M_{1}$ was the non-fuzzy weight of fees and commission expenses. Since $M_{l}$ was a non-fuzzy number, it could be normalised using equation (10). The sum of the overall relative weights for each criterion should be equal to 1 . The same procedures were applied to compute the overall relative weights for each input factor and the output factor for every expert. Table 5 displays the priorities of inputs and its ratios based on the decision makers. Additionally, the values were rounded off to four decimal places. Meanwhile, Table 6 depicts the priorities of outputs and the ratio given by the decision makers. 
Table 5. Priorities of Input Factors by Decision Makers

\begin{tabular}{|l|l|l|l|l|}
\cline { 2 - 5 } \multicolumn{1}{c|}{} & DM1 & DM2 & DM3 & DM4 \\
\hline$v_{1}$ & 0.1 & 0.2576 & 0.9 & 0.9 \\
\hline$v_{2}$ & 0.9 & 0.7424 & 0.1 & 0.1 \\
\hline$\frac{v_{2}}{v_{1}}$ & 9.0000 & 2.8812 & 9.0000 & 9.0000 \\
\hline
\end{tabular}

Table 6. Priorities of Output Factors by Decision Makers

\begin{tabular}{|l|l|l|l|l|}
\cline { 2 - 5 } \multicolumn{1}{c|}{} & DM1 & DM2 & DM3 & DM4 \\
\hline$u_{1}$ & 0.6439 & 0.7965 & 0.5 & 0.1 \\
\hline$u_{2}$ & 0.3561 & 0.2035 & 0.5 & 0.9 \\
\hline$\frac{u_{2}}{u_{1}}$ & 0.5530 & 0.2555 & 1.0000 & 9.0000 \\
\hline
\end{tabular}

The last row of Table 5 shows the ratios of inputs. These results were used to set lower and upper bounds of assurance region. The maximum value of ratio $\frac{v_{2}}{v_{1}}$ was 9.0000 whereas the minimum value of ratio $\frac{v_{2}}{v_{1}}$ was 2.8812. Therefore, the range of $\frac{v_{2}}{v_{1}}$ was $2.8812 \leq \frac{v_{2}}{v_{1}} \leq 9.0000$. The last row of Table 6 shows the ratios of output. The maximum value of ratio $\frac{u_{2}}{u_{1}}$ was 9.0000 whereas the minimum value of ratio $\frac{u_{2}}{u_{1}}$ was 0.2555 . Therefore, the range of $\frac{u_{2}}{u_{1}}$ was $0.2555 \leq \frac{u_{2}}{u_{1}} \leq 9.0000$. Both the ratio ranges were integrated into a standard CCR with an input orientation model to generate the efficiency scores for 22 life insurance and takaful companies.

\section{Efficiency Analysis}

Table 7 show the description of the DMUs, while Table 8 and Table 9 present the weight distributions of input and output variables and efficiency scores of the companies for DEA and DEA-AR/FAHP models in 2017 and 2018. Both models were solved using PIM-DEA Software (Emrouznejad \& Thanassoulis, 2014). Columns 2 and 3 in each table display the values of output weights whereas columns 4 and 5 in each table display the values of input weights via CCR model. On the other hand, columns 6 and 7 show the values of output weights whereas columns 8 and 9 show the values of input weights based on DEA-AR/FAHP. These tables show that each company from both the models was assigned a set of weights with values that varied from one company to another. The weights and efficiency scores derived from DEAAR/FAHP model were different from those acquired via the DEA model. The findings revealed that many zero weights were assigned to the selected input and output variables in DEA model as a result of the versatile selection of weights to input and output that indicated the respective input and output factors that were ignored in the efficiency assessment. These unreasonable situations were not found in DEA-AR/FAHP model because the input and output weights were larger than zero. This indicated that the model had assigned weights to all input and output factors. No inputs or outputs were assigned with zero weight in the two-year 
under study. Therefore, all the input and output factors were considered in the evaluation of efficiency. DEA-AR/FAHP considered all input and output factors, and therefore it produced more reasonable weights for the inputs and outputs. Hence, the efficiency results of DEAAR/FAHP were more accurate, and it reflected realistic decision-making, specifically to evaluate the efficiency of life insurance and takaful companies.

Table 7. Description of the DMUs

\begin{tabular}{llll}
\hline DMU & Description & DMU & Description \\
\hline DMU1 & Allianz Life Insurance Malaysia Berhad & DMU12 & Hong Leong Assurance Berhad \\
DMU2 & AIA Berhad & DMU13 & AmMetLife Assurance Berhad \\
DMU3 & AXA Affin Life Insurance Berhad & DMU14 & HSBC Amanah Takaful Berhad \\
DMU4 & Great Eastern Life Assurance (Malaysia & DMU15 & Prudential BSN Takaful Berhad \\
& Berhad) & & \\
DMU5 & Manulife Insurance Berhad & DMU16 & Sun Life Malaysia Takaful Berhad \\
DMU6 & MCIS Insurance Berhad & DMU17 & Zurich Takaful Malaysia Berhad \\
DMU7 & Prudential Assurance Malaysia Berhad & DMU18 & AlA Public Takaful Berhad \\
DMU8 & Sun Life Malaysia Assurance Berhad & DMU19 & Etiqa Family Takaful Berhad \\
DMU9 & Tokio Marine Life Insurance Malaysia & DMU20 & AmMetLife Takaful Berhad \\
& Berhad & & \\
DMU10 & Gibraltar BSN Life Berhad & DMU21 & Great Eastern Takaful \\
DMU11 & Zurich Life Insurance Malaysia Berhad & DMU22 & Hong Leong MSIG Takaful Takaful \\
& & & Berhad \\
\hline
\end{tabular}

The following Table 8 and Table 9 show the weight distributions of input and output variables and efficiency scores of the companies for DEA and DEA-AR/FAHP models in 2017 and 2018. As mentioned earlier, there were many zero weights assigned to selected input and output factors when using standard DEA model. However, zero weights disappeared when DEA-AR/FAHP was adopted, whereby all weight values were greater than zero. This infers that all factors were included in efficiency evaluation. Weight restrictions were shown to have successfully overcome zero weight issue. In addition, with imposition of weight restrictions, almost all the efficiency scores in DEA-AR/FAHP dropped substantially, whereby the values were either lower or equal to those obtained in standard DEA model. These results prove that unbounded standard DEA had overestimated efficiency scores. 
INTERNATIONAL JOURNAL OF ACADEMIC RESEARCH IN BUSINESS AND SOCIAL SCIENCES Vol. 11, No. 11, 2021, E-ISSN: 2222-6990 (C) 2021 HRMARS

Table 8. Weight Distribution of Output and Input Variables via DEA and DEA- AR/FAHP Models in 2017

\begin{tabular}{|c|c|c|c|c|c|c|c|c|c|c|}
\hline \multirow[b]{4}{*}{ DMU } & \multicolumn{10}{|c|}{2017} \\
\hline & \multicolumn{5}{|c|}{ DEA } & \multicolumn{5}{|c|}{ DEA-AR/FAHP } \\
\hline & \multicolumn{2}{|c|}{ Output Weights } & \multicolumn{2}{|c|}{ Input Weights } & \multirow{2}{*}{$\begin{array}{c}\text { Efficiency } \\
\text { Score }\end{array}$} & \multicolumn{2}{|c|}{ Output Weights } & \multicolumn{2}{|c|}{ Input Weights } & \multirow{2}{*}{$\begin{array}{c}\text { Efficiency } \\
\text { Score }\end{array}$} \\
\hline & $u_{1}$ & $u_{2}$ & $v_{1}$ & $v_{2}$ & & $u_{1}$ & $u_{2}$ & $v_{1}$ & $v_{2}$ & \\
\hline DMU1 & 0.0057 & 0.0000 & 0.0039 & 0.0034 & 0.7277 & 0.0042 & 0.0011 & 0.0021 & 0.0059 & 0.6391 \\
\hline DMU2 & 0.0021 & 0.0001 & 0.0015 & 0.0013 & 1.0000 & 0.0014 & 0.0004 & 0.0007 & 0.0019 & 0.8196 \\
\hline DMU3 & 0.0240 & 0.0000 & 0.0164 & 0.0143 & 0.6880 & 0.0137 & 0.0035 & 0.0067 & 0.0193 & 0.4399 \\
\hline DMU4 & 0.0018 & 0.0003 & 0.0014 & 0.0012 & 1.0000 & 0.0001 & 0.0013 & 0.0008 & 0.0022 & 1.0000 \\
\hline DMU5 & 0.0190 & 0.0000 & 0.0130 & 0.0114 & 1.0000 & 0.0106 & 0.0027 & 0.0052 & 0.0149 & 0.6683 \\
\hline DMU6 & 0.0180 & 0.0029 & 0.0146 & 0.0120 & 0.7214 & 0.0132 & 0.0036 & 0.0065 & 0.0187 & 0.5965 \\
\hline DMU7 & 0.0018 & 0.0000 & 0.0012 & 0.0011 & 0.7160 & 0.0014 & 0.0003 & 0.0007 & 0.0019 & 0.6273 \\
\hline DMU8 & 0.0200 & 0.0000 & 0.0226 & 0.0079 & 0.6176 & 0.0107 & 0.0027 & 0.0052 & 0.0150 & 0.3782 \\
\hline DMU9 & 0.0109 & 0.0016 & 0.0090 & 0.0069 & 0.8308 & 0.0071 & 0.0019 & 0.0035 & 0.0100 & 0.6082 \\
\hline DMU10 & 0.0135 & 0.0350 & 0.0900 & 0.0078 & 1.0000 & 0.0103 & 0.0028 & 0.0051 & 0.0146 & 0.2423 \\
\hline DMU11 & 0.0000 & 0.0097 & 0.0096 & 0.0085 & 0.7383 & 0.0008 & 0.0074 & 0.0043 & 0.0123 & 0.5971 \\
\hline DMU12 & 0.0056 & 0.0000 & 0.0038 & 0.0033 & 1.0000 & 0.0046 & 0.0012 & 0.0022 & 0.0065 & 1.0000 \\
\hline DMU13 & 0.0000 & 0.0220 & 0.0462 & 0.0035 & 0.7440 & 0.0009 & 0.0082 & 0.0048 & 0.0137 & 0.2976 \\
\hline DMU14 & 0.0957 & 0.0000 & 0.1079 & 0.0379 & 1.0000 & 0.0387 & 0.0099 & 0.0188 & 0.0543 & 0.4844 \\
\hline DMU15 & 0.0053 & 0.0000 & 0.0036 & 0.0032 & 0.4982 & 0.0034 & 0.0009 & 0.0017 & 0.0048 & 0.3361 \\
\hline DMU16 & 0.0201 & 0.0000 & 0.0227 & 0.0079 & 0.5277 & 0.0106 & 0.0027 & 0.0051 & 0.0148 & 0.3090 \\
\hline DMU17 & 0.0278 & 0.0000 & 0.0190 & 0.0166 & 0.4391 & 0.0191 & 0.0049 & 0.0093 & 0.0268 & 0.3312 \\
\hline DMU18 & 0.0141 & 0.0000 & 0.0096 & 0.0084 & 0.5269 & 0.0097 & 0.0025 & 0.0047 & 0.0135 & 0.3787 \\
\hline DMU19 & 0.0104 & 0.0015 & 0.0086 & 0.0065 & 1.0000 & 0.0007 & 0.0059 & 0.0034 & 0.0099 & 0.7952 \\
\hline DMU20 & 0.1598 & 0.0000 & 0.5236 & 0.0000 & 0.4635 & 0.0535 & 0.0137 & 0.0260 & 0.0749 & 0.1809 \\
\hline DMU21 & 0.0223 & 0.0000 & 0.0152 & 0.0133 & 0.3556 & 0.0135 & 0.0035 & 0.0066 & 0.0189 & 0.2299 \\
\hline DMU22 & 0.1020 & 0.0000 & 0.0695 & 0.0608 & 0.5028 & 0.0596 & 0.0152 & 0.0290 & 0.0835 & 0.3423 \\
\hline
\end{tabular}


INTERNATIONAL JOURNAL OF ACADEMIC RESEARCH IN BUSINESS AND SOCIAL SCIENCES Vol. 11, No. 11, 2021, E-ISSN: 2222-6990 @ 2021 HRMARS

Table 9. Weight Distribution of Output and Input Variables via DEA and DEA- AR/FAHP Models in 2018

\begin{tabular}{|c|c|c|c|c|c|c|c|c|c|c|}
\hline \multirow[b]{4}{*}{ DMU } & \multicolumn{10}{|c|}{2018} \\
\hline & \multicolumn{5}{|c|}{ DEA } & \multicolumn{5}{|c|}{ DEA-AR/FAHP } \\
\hline & \multicolumn{2}{|c|}{ Output Weights } & \multicolumn{2}{|c|}{ Input Weights } & \multirow{2}{*}{$\begin{array}{c}\text { Efficiency } \\
\text { Score }\end{array}$} & \multicolumn{2}{|c|}{ Output Weights } & \multicolumn{2}{|c|}{ Input Weights } & \multirow{2}{*}{$\begin{array}{c}\text { Efficiency } \\
\text { Score }\end{array}$} \\
\hline & $u_{1}$ & $u_{2}$ & $v_{1}$ & $v_{2}$ & & $u_{1}$ & $u_{2}$ & $v_{1}$ & $V_{2}$ & \\
\hline DMU1 & 0.0060 & 0.0000 & 0.0035 & 0.0044 & 0.7692 & 0.0043 & 0.0011 & 0.0009 & 0.0085 & 0.6537 \\
\hline DMU2 & 0.0021 & 0.0000 & 0.0015 & 0.0011 & 1.0000 & 0.0012 & 0.0003 & 0.0006 & 0.0018 & 0.7401 \\
\hline DMU3 & 0.0277 & 0.0000 & 0.0201 & 0.0152 & 0.6786 & 0.0142 & 0.0036 & 0.0074 & 0.0214 & 0.4005 \\
\hline DMU4 & 0.0021 & 0.0001 & 0.0015 & 0.0013 & 1.0000 & 0.0001 & 0.0013 & 0.0008 & 0.0024 & 1.0000 \\
\hline DMU5 & 0.0208 & 0.0000 & 0.0151 & 0.0114 & 1.0000 & 0.0102 & 0.0026 & 0.0053 & 0.0153 & 0.5921 \\
\hline DMU6 & 0.0211 & 0.0010 & 0.0156 & 0.0126 & 0.6635 & 0.0130 & 0.0033 & 0.0068 & 0.0195 & 0.5198 \\
\hline DMU7 & 0.0018 & 0.0000 & 0.0012 & 0.0011 & 0.7099 & 0.0013 & 0.0003 & 0.0007 & 0.0019 & 0.5786 \\
\hline DMU8 & 0.0200 & 0.0000 & 0.0146 & 0.0110 & 0.6173 & 0.0099 & 0.0025 & 0.0052 & 0.0149 & 0.3502 \\
\hline DMU9 & 0.0115 & 0.0002 & 0.0086 & 0.0063 & 0.8367 & 0.0063 & 0.0016 & 0.0033 & 0.0095 & 0.5693 \\
\hline DMU10 & 0.0036 & 0.0456 & 0.1130 & 0.0046 & 1.0000 & 0.0100 & 0.0025 & 0.0052 & 0.0149 & 0.2037 \\
\hline DMU11 & 0.0000 & 0.0103 & 0.0126 & 0.0067 & 0.7143 & 0.0008 & 0.0069 & 0.0043 & 0.0124 & 0.5082 \\
\hline DMU12 & 0.0062 & 0.0000 & 0.0036 & 0.0045 & 1.0000 & 0.0047 & 0.0012 & 0.0010 & 0.0094 & 0.9470 \\
\hline DMU13 & 0.0016 & 0.0202 & 0.0502 & 0.0021 & 0.6799 & 0.0096 & 0.0025 & 0.0050 & 0.0144 & 0.3222 \\
\hline DMU14 & 0.1106 & 0.0168 & 0.1700 & 0.0365 & 1.0000 & 0.0396 & 0.0101 & 0.0206 & 0.0594 & 0.3869 \\
\hline DMU15 & 0.0054 & 0.0000 & 0.0035 & 0.0032 & 0.5066 & 0.0032 & 0.0008 & 0.0017 & 0.0048 & 0.3166 \\
\hline DMU16 & 0.0210 & 0.0000 & 0.0292 & 0.0060 & 0.4520 & 0.0093 & 0.0024 & 0.0048 & 0.0139 & 0.2280 \\
\hline DMU17 & 0.0273 & 0.0000 & 0.0178 & 0.0166 & 0.5115 & 0.0173 & 0.0044 & 0.0090 & 0.0260 & 0.3526 \\
\hline DMU18 & 0.0118 & 0.0000 & 0.0077 & 0.0072 & 0.5464 & 0.0080 & 0.0020 & 0.0042 & 0.0120 & 0.3896 \\
\hline DMU19 & 0.0116 & 0.0002 & 0.0087 & 0.0064 & 1.0000 & 0.0061 & 0.0016 & 0.0032 & 0.0091 & 0.6977 \\
\hline DMU20 & 0.1187 & 0.0000 & 0.1650 & 0.0339 & 0.5188 & 0.0427 & 0.0109 & 0.0222 & 0.0640 & 0.2064 \\
\hline DMU21 & 0.0205 & 0.0000 & 0.0149 & 0.0112 & 0.4211 & 0.0119 & 0.0030 & 0.0062 & 0.0178 & 0.2597 \\
\hline DMU22 & 0.0871 & 0.0000 & 0.0634 & 0.0478 & 0.6562 & 0.0472 & 0.0121 & 0.0246 & 0.0708 & 0.3981 \\
\hline
\end{tabular}

Table 10 is a summary of the estimate efficiency scores obtained via DEA-AR/FAHP in 2017 and 2018. The values were rounded to four decimal places. It presents efficiency scores of the companies that applied the DEA-AR/FAHP model. 
Table 10. Efficiency scores measured by DEA-AR/FAHP

\begin{tabular}{|l|c|c|}
\hline Life Insurance Companies & $2017(\%)$ & 2018 (\%) \\
\hline Allianz Life Insurance Malaysia Berhad & 0.6391 & 0.6537 \\
\hline AIA Berhad & 0.8196 & 0.7401 \\
\hline AXA Affin Life Insurance Berhad & 0.4399 & 0.4005 \\
\hline $\begin{array}{l}\text { Great Eastern Life Assurance (Malaysia } \\
\text { Berhad) }\end{array}$ & 1.0000 & 1.0000 \\
\hline Manulife Insurance Berhad & 0.6683 & 0.5921 \\
\hline MCIS Insurance Berhad & 0.5965 & 0.5198 \\
\hline Prudential Assurance Malaysia Berhad & 0.6273 & 0.5786 \\
\hline Sun Life Malaysia Assurance Berhad & 0.3782 & 0.3502 \\
\hline $\begin{array}{l}\text { Tokio Marine Life Insurance Malaysia } \\
\text { Berhad }\end{array}$ & 0.6082 & 0.5693 \\
\hline Gibraltar BSN Life Berhad & 0.2423 & 0.2037 \\
\hline Zurich Life Insurance Malaysia Berhad & 0.5971 & 0.5082 \\
\hline Hong Leong Assurance Berhad & 1.0000 & 0.9470 \\
\hline AmMetLife Assurance Berhad & 0.2976 & 0.3222 \\
\hline HSBC Amanah Takaful Berhad & 0.4844 & 0.3869 \\
\hline Prudential BSN Takaful Berhad & 0.3361 & 0.3166 \\
\hline Sun Life Malaysia Takaful Berhad & 0.3090 & 0.2280 \\
\hline Zurich Takaful Malaysia Berhad & 0.3312 & 0.3526 \\
\hline AIA Public Takaful Berhad & 0.3787 & 0.3896 \\
\hline Etiqa Family Takaful Berhad & 0.7952 & 0.6977 \\
\hline AmMetLife Takaful Berhad & 0.1809 & 0.2064 \\
\hline Great Eastern Takaful & 0.2299 & 0.2597 \\
\hline Hong Leong MSIG Takaful Takaful Berhad & 0.3423 & 0.3981 \\
\hline
\end{tabular}

Table 10 depicts fluctuations in the efficiency scores among the majority of the companies in 2017 and 2018. In 2017, two departments obtained an efficiency score of one, predominantly the efficient units for Great Eastern Life Assurance (Malaysia Berhad) and Hong Leong Assurance Berhad. These departments performed the best in comparison to others because they utilised resources efficiently to maximise output The Insurance Services Malaysia (ISM) reported in 2017 that more than 1.2 million Malaysians had a life insurance policy with Great Eastern Life Assurance Malaysia Berhad. It is the largest life insurance company in Malaysia. Moreover, Great Eastern Life Assurance (Malaysia Berhad) earned the highest investment income in 2017. Nonetheless the companies that did not obtain score unity were deemed inefficient. The AIA Berhad scored the third highest score, followed by Etiqa Family Takaful Berhad, and Manulife Insurance Berhad. AmMetLife Takaful Berhad is the least efficient company with lowest efficiency score.

Great Eastern Life Assurance (Malaysia Berhad) had once again topped the list as the most efficient company in 2018. This resulted from a high investment income in 2018. Therefore, the Great Eastern Life Assurance (Malaysia Berhad) had been efficient for two consecutive years. The other companies should adopt Great Eastern's strategies and practices to transform their input and output. Hong Leon Assurance Berhad recorded the second most efficient company with an efficiency score of 0.947 , followed by AIA Berhad, and Etiqa Family Takaful Berhad. These three companies were consistently the top five (5) most efficient life 
insurance companies in Malaysia. On the other hand, Gibraltar BSN Life Berhad was the least efficient company in 2018 with the lowest efficiency scores. On the other hand, Etiqa Family Takaful Berhad was one of the top five takaful operators throughout the period of analysis. This proved that conventional insurance companies were more efficient in allocating input to produce optimal output in comparison to the takaful operators. Therefore, the present research coincided with the study conducted by (Antonio et.al., 2013; Saad, 2012).

\section{Conclusion}

The present study revealed that the DEA worked better when integrated with other methods to overcome its shortfalls. It is shown that the DEA-AR/FAHP method improved discrimination power in DEA method where fewer number of efficient units are identified. This makes the hybrid method is more practical for measuring efficiency of insurance and takaful companies. Moreover, the hybrid model had effectively eliminated zero weights assigned to input and output factors. This indicated that all input and output factors were considered to evaluate the efficiency of the companies, hence producing more reasonable weights for inputs and outputs and reflected the realistic decision-making situation. Therefore, the results obtained via the hybrid method were more accurate and practical for two significant reasons. First, it incorporated decision makers' judgement on the importance of inputs and outputs. Second, it regarded all inputs and outputs as important factors. These findings were imperative and benefited the top management of insurance and takaful companies. This information helped these companies in making rational judgement and managing their resources efficiently. The efficient companies can be regarded as the model for the other departments to benchmark. It is suggested that the inefficient companies to emulate the best practice of efficient companies in transforming their inputs to outputs in order to attain higher level of efficiency. Moreover, the top management can use the efficiency scores to come out with detailed business strategies to improve the companies' performance. 


\section{References}

Abd. Majid, M. S., Abdul Hamid., \& Faradilla. (2017). Assessing the productivity of insurance companies in Indonesia: A non-parametric approach. Journal of Applied Economic Sciences, 12(6), 1593-1605.

Abidin, Z., \& Cabanda, E. (2011). Efficiency of non-life insurance in Indonesia. Journal of Economics, Business and Accountancy Ventura, 14(3), $197-202$.

Allen, R., Athanassopoulos, A., Dyson, R., \& Thanassoulis, E. (1997). Weights restrictions and value judgements in data envelopment analysis: evolution, development and future directions. Annals of Operations Research, 73, 13-34.

Almulhim, T. (2019). Analysis of takaful vs. conventional insurance firms' efficiency: Twostage DEA of Saudi Arabia's insurance market. Cogent Business \& Management, 6(1), 1633807.

Antonio, M. S., Ali, M. M., \& Akbar, N. (2013). A comparative analysis of the efficiency of takaful and conventional insurance in Malaysia. International Journal of Excellence in Islamic Banking and Finance, 182(881), 1-13.

Bal, H., Örkcü, H. H., \& Çelebioğlu, S. (2010). Improving the discrimination power and weights dispersion in the data envelopment analysis. Computers \& Operations Research, 37(1), 99-107.

Bank Negara of Malaysia. (2020). Retrieved from https://www.bnm.gov.my/index.php?ch=li\&cat=insurance\&type $=$ L\&fund $=0 \& c u=0$

Buckley, J. J. (1985). Fuzzy hierarchical analysis. Fuzzy Sets and Systems, 17(3), 233-247.

Chang, D.-Y. (1996). Applications of the extent analysis method on fuzzy AHP. European Journal of Operational Research, 95(3), 649-655.

Charnes, A., Cooper, W. W., \& Rhodes, E. (1978). Measuring the efficiency of decision making units. European Journal of Operational Research, 2(6), 429-444.

Chen, F. C., Liu, Z. J., \& Kweh, Q. L. (2014). Intellectual capital and productivity of Malaysian general insurers. Economic Modelling, 36, 413-420.

Coelli, T. J., Rao, D. S. P., O'Donnell, C. J., \& Battese, G. E. (2005). An introduction to efficiency and productivity analysis. Springer Science \& Business Media.

Cooper, W. W., Seiford, L. M., \& Tone, K. (2006). Introduction to data envelopment analysis and its uses: with DEA-solver software and references. Springer Science \& Business Media.

Cummins, J. D., Tennyson, S., \& Weiss, M. A. (1999). Consolidation and efficiency in the US life insurance industry. Journal of Banking \& Finance, 23(2-4), 325-357.

Deng, H. (1999). Multicriteria analysis with fuzzy pairwise comparison. International Journal of Approximate Reasoning, 21(3), 215-231.

Dyson, R. G., Allen, R., Camanho, A. S., Podinovski, V. V., Sarrico, C. S., \& Shale, E. A. (2001). Pitfalls and protocols in DEA. European Journal of Operational Research, 132(2), 245259.

Eling, M., \& Luhnen, M. (2010). Efficiency in the international insurance industry: A crosscountry comparison. Journal of Banking \& Finance, 34(7), 1497-1509.

Emrouznejad, A., \& Thanassoulis, E. (2014). Introduction to performance improvement management software (PIM-DEA). In Handbook of Research on Strategic Performance Management and Measurement Using Data Envelopment Analysis (pp. 256-275). IGI Global. 
Kahraman, C., Cebeci, U., \& Ruan, D. (2004). Multi-attribute comparison of catering service companies using fuzzy AHP: The case of Turkey. International Journal of Production Economics, 87(2), 171-184.

Kao, C., \& Hwang, S.-N. (2008). Efficiency decomposition in two-stage data envelopment analysis: An application to non-life insurance companies in Taiwan. European Journal of Operational Research, 185(1), 418-429.

Khalili, M., Camanho, A. S., Portela, M. C. A. S., \& Alirezaee, M. R. (2010). The measurement of relative efficiency using data envelopment analysis with assurance regions that link inputs and outputs. European Journal of Operational Research, 203(3), 761-770.

Kubler, S., Robert, J., Derigent, W., Voisin, A., \& Le Traon, Y. (2016). A state-of the-art survey \& testbed of fuzzy AHP (FAHP) applications. Expert Systems with Applications, 65, 398422.

Life Insurance Association of Malaysia. (2019). Retrived from http://www.liam.org.my/images/news/en/SmartInvestor_LIAM_June_2019.pdf

Mansur, S., \& Radam, A. (2000). Productivity and efficiency performance of the Malaysian life insurance industry. Jurnal Ekonomi Malaysia, 34, 93-105.

Masud, M. M., Rana, M. S., Mia, M. A., \& Saifullah, M. K. (2019). How productive are life insurance institutions in Malaysia? A Malmquist approach. Journal of Asian Finance, Economics and Business, 6(1), 241-248.

Matsawali, M. S., Abdullah, M. F., Yeo, C.P., Abidin, S. Y., Zaini, M. M., Ali, H. M., Alani, F., \& Yaacob, H. (2012). A study on takaful and conventional insurance preferences: The case of Brunei. International Journal of Business and Social Science, 3(22), 163- 176.

Meador, J. W., Ryan, H. E., \& Schellhorn, C. D. (2000). Product focus versus diversification: Estimates of X-Efficiency for the US life insurance industry. In T. P. Harker and S. A. Zenios (Eds.), Performance of financial institutions: Efficiency, Innovation, Regulation (175-198). Cambridge University Press.

Mohamad, N. S., Paszil, A. N. F., \& Hashim, N. Z. (2019). A two-stage model in evaluating the efficiency of life insurance companies based on DEA/AHP method. Universiti Teknologi MARA Negeri Sembilan, Malaysia.

Ozdemir, M. S., \& Saaty, T. L. (2006). The unknown in decision making. What to do about it. European Journal of Operational Research, 174, 349-359.

Premachandra, I. (2001). Controlling factor weights in data Envelopment analysis by incorporating decision maker's value judgement: An approach based on AHP. International journal of information and management sciences, 12(2), 67-82.

Rusydiana, A. S., \& Nugroho, T. (2017). Measuring efficiency of life insurance institution in Indonesia: Data Envelopment Analysis approach. Global Review of Islamic Economics and Business, 5(1), 12-24.

Saad, N. M. (2012). An analysis on the efficiency of takaful and insurance companies in Malaysia: a non-parametric approach. Review of Integrative Business \& Economics Research, 1(1), 33-56.

Saad, N. M., Abd Majid, M. S., Yusof, M. R., Yusof, J., Duasa, A., \& Rahim, A. (2006). Measuring efficiency of insurance and takaful companies in Malaysia using Data Envelopment Analysis (DEA). Review of Islamic Economics, 10, 5-26.

Saad, N. M., \& Idris, N. E. H. (2011). Efficiency of life insurance companies in Malaysia and Brunei: A comparative analysis. International Journal of Humanities and Social Science, 1(3), 111-122. 
Saaty, T. L. (1994). Highlights and critical points in the theory and application of the Analytic Hierarchy Process. European Journal of Operational Research, 74, 426-447.

Shieh, H. S., Hu, J. L., \& Ang, Y. Z. (2020). Efficiency of Life Insurance Companies: An Empirical Study in Mainland China and Taiwan. SAGE Open, 10(1), 2158244020902060.

Vahidnia, M. H., Alesheikh, A. A., \& Alimohammadi, A. (2009). Hospital site selection using fuzzy AHP and its derivatives. Journal of Environmental Management, 90(10), 30483056.

Van Laarhoven, P. J., \& Pedrycz, W. (1983). A fuzzy extension of Saaty's priority theory. Fuzzy Sets and Systems, 11, 229-241.

Kumar, V. N., \& Ganesh, L. S. (1996). An empirical analysis of the use of the Analytic Hierarchy Process for estimating membership values in a fuzzy set. Fuzzy Sets and Systems, 82(1), $1-16$.

Wang, Y.-M., Luo, Y., \& Hua, Z. (2008). On the extent analysis method for fuzzy AHP and its applications. European Journal of Operational Research, 186(2), 735-747.

Wang, Z. L., Kim, J., Selvachandran, G., Smarandache, F., Son, L. H., Abdel-Basset, M., Thong, P. H., \& Ismail, M. (2019). Decision Making Methods for Evaluation of Efficiency of General Insurance Companies in Malaysia: A Comparative Study. IEEE Access, 7, 160637-160649.

Zadeh, L. A. (1965). Fuzzy sets. Information and Control, 8, 338-353. 